\title{
Changes in Phytoavailability of Cadmium, Copper, Lead, and Zinc after Application with Eggshell in Contaminated Agricultural Soil
}

\author{
Rog-Young Kim, and Jae E. Yang* \\ Department of Biological Environment, Kangwon National University, 200-701, Chuncheon, Republic of Korea
}

(Received: January 14 2014, Accepted: February 5 2014)

\begin{abstract}
Agricultural soils surrounding mine areas in South Korea are often contaminated with multiple metals such as $\mathbf{C d}$, $\mathrm{Pb}$ and $\mathrm{Zn}$. It poses potential risks to plants, soil organisms, groundwater, and eventually human health. The aim of this study was to examine the changes in phytoavailability of $\mathrm{Cd}, \mathrm{Cu}, \mathrm{Pb}$ and $\mathrm{Zn}$ after application with calcined eggshell (CES; $0,1,3$, and 5\% W/W) in an agricultural soil contaminated by mine tailings. The contents of $\mathrm{Cd}$, $\mathrm{Cu}, \mathrm{Pb}$ and $\mathrm{Zn}$ in soils were 8.79, 65.4, 1602, and $692 \mathrm{mg} \mathrm{kg}^{-1}$ (aqua regia dissolution), respectively. The experiments were conducted with lettuce (Lactuca sativa $\mathrm{L}$. var. longifolia) grown under greenhouse conditions during a 30-d period. $\mathrm{NH}_{4} \mathrm{NO}_{3}$ solution was used to examine the mobile fraction of these metals in soil. The application of CES dramatically increased soil $\mathrm{pH}$ and inorganic carbon content in soil due to $\mathrm{CaO}$ and $\mathrm{CaCO}_{3}$ of CES. The increased soil pH decreased the mobile fraction of $\mathrm{Cd}, \mathrm{Pb}, \mathrm{Zn}$ : from 3.49 to $<0.01 \mathrm{mg} \mathrm{kg}^{-1}$ for Cd, from 79.4 to $1.75 \mathrm{mg} \mathrm{kg}^{-1}$ for $\mathrm{Pb}$, and from 29.6 to $1.13 \mathrm{mg} \mathrm{kg}^{-1}$ for $\mathrm{Zn}$ with increasing treatment of CES from 0 to $5 \%$ In contrast, the mobile fraction of $\mathrm{Cu}$ was increased from 0.05 to $3.08 \mathrm{mg} \mathrm{kg}^{-1}$, probably due to the formation of soluble $\mathrm{CuCO}_{3}{ }^{0}$ and $\mathrm{Cu}$-organic complex. This changes in the mobile fraction resulted in a diminished uptake of $\mathrm{Cd}, \mathrm{Pb}$ and $\mathrm{Zn}$ by lettuce and an increased uptake of $\mathrm{Cu}$ : from 4.19 to $<0.001 \mathrm{mg} \mathrm{kg}^{-1}$ dry weight (DW) for Cd, from 0.78 to $<0.001 \mathrm{mg} \mathrm{kg}^{-1} \mathrm{DW}$ for Pb, and from 133 to $50.0 \mathrm{mg} \mathrm{kg}^{-1} \mathrm{DW}$ for $\mathrm{Zn}$ and conversely, from 3.79 up to $8.21 \mathrm{~kg}^{-1} \mathrm{DW}$ for $\mathrm{Cu}$. The increased contents of $\mathrm{Cu}$ in lettuce shoots did not exceed the toxic level of $>25 \mathrm{mg}$ $\mathrm{kg}^{-1} \mathrm{DW}$. The mobile contents of these metals in soils showed a strong relationship with their contents in plant roots and shoots. These results showed that $\mathrm{CES}$ effectively reduced the phytoavailability of $\mathrm{Cd}, \mathrm{Pb}$, and $\mathrm{Zn}$ to lettuce but elevated that of $\mathrm{Cu}$ in consequence of the changed binding forms of $\mathrm{Cd}, \mathrm{Cu}, \mathrm{Pb}$, and $\mathrm{Zn}$ in soils. Based on these conclusions, $\mathrm{CES}$ can be used as an effective immobilization agent for $\mathrm{Cd}, \mathrm{Pb}$ and $\mathrm{Zn}$ in contaminated soils. However, the CES should be applied in restricted doses due to too high increased pH in soils.
\end{abstract}

Key words: Immobilization, Lettuce, Mobile content, Mine areas, $\mathrm{NH}_{4} \mathrm{NO}_{3}$
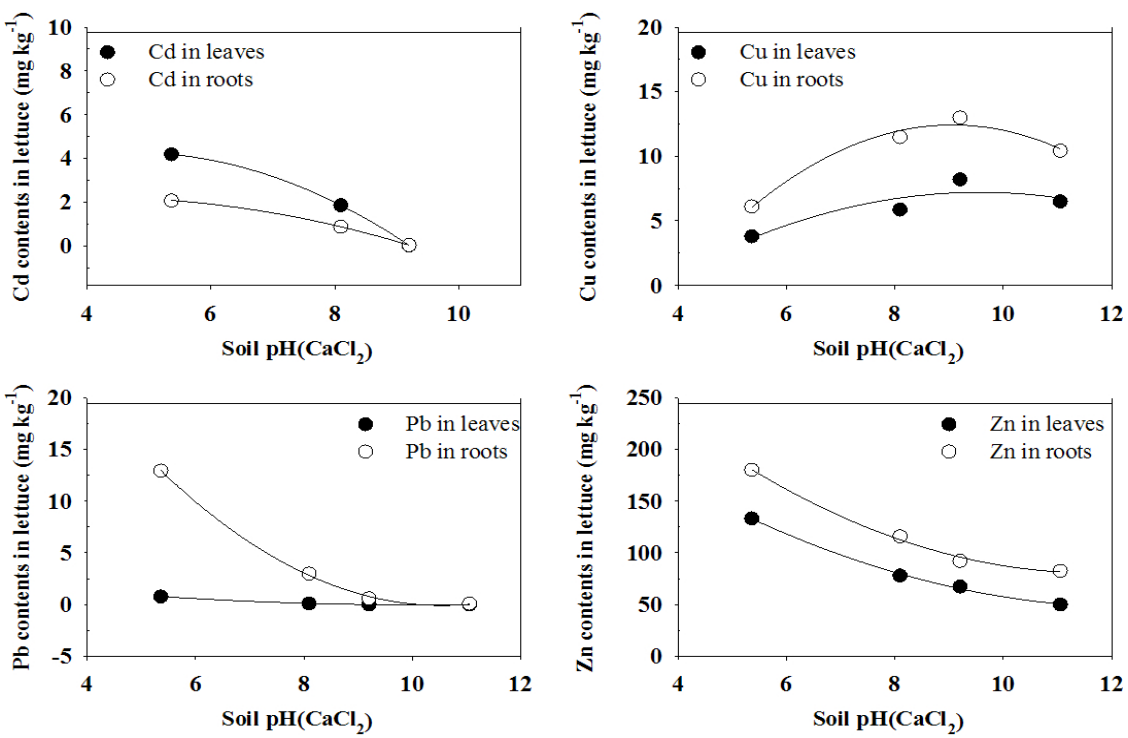

$\mathrm{Cd}, \mathrm{Cu}, \mathrm{Pb}$, and $\mathrm{Zn}$ contents in lettuce roots and leaves depending on soil $\mathrm{pH}\left(\mathrm{CaCl}_{2}\right)$ after treatment with calcined eggshell.

\footnotetext{
*Corresponding author : Phone: +82332506446, Fax: +82332416640, E-mail: yangjay@kangwon.ac.kr

${ }^{\S}$ Acknowledgement: This study was carried out with the support of "2009 Post-Doctoral Research Program", National Academy of Agricultural Science, Rural Development Administration, Republic of Korea.
} 


\section{Introduction}

최근 들어 외국에서는 오염된 토양을 평가하고 복원하기 위한 법적인 규제로써 전함량 대신에 노출과 생물 유효도를 고려하여 평가하려는 움직임이 있다 (Derz et al., 2012; ISO 17402, 2008; Meers et al., 2007). 토양 내 존재하는 중금속의 생태학적 위해도 및 생물 유효도를 평가하기 위해서는 전함 량 보다는 생물학적 이용 가능한 함량을 파악하는 것이 중 요하다 (Bruemmer et al., 1986; Gupta et al., 1996; Kim et al., 2007). 수많은 연구자들이 생물학적 유효도를 평가하기 위한 다양한 연구들을 진행하여 왔으나, 아직 생물 유효도를 평 가하기 위한 표준 분석법이 개발되어 있지 않은 실정이다. 그럼에도 불구하고, $1 \mathrm{M} \mathrm{NH}_{4} \mathrm{NO}_{3}$ 추출액은 토양 내 수용성 및 용해성 금속-유기 복합체 및 교환성 원소들을 추출할 수 있기 때문에 (이동태 함량), 중금속의 작물 유효도 평가에 자주 사용되어 왔다 (ISO 17402, 2008; Meers et al., 2007). 중 금속의 토양 내 용해도 및 이동성은 $\mathrm{pH}$, 용해성 유기물, 수 분 함량, 점토 함량, $\mathrm{CEC}$ 등과 같은 인자에 의해 영향을 받 으며, 식물의 종류와 중금속의 종류에 따라서도 식물 유효 도가 달라진다 (Hund-Rinke and Koerdel, 2003; Lanno et al., 2004; Semple et al., 2004). 일반적으로 $\mathrm{Cl}^{-}, \mathrm{OH}, \mathrm{SO}_{4}^{2-}, \mathrm{HCO}_{3}^{-}$와 같은 무기 음이온과 플브산, 부식산과 같은 용해성 유기탄소 (DOC) 의 존재는 토양 용액 중 중금속의 용해도를 증가시키는 것으 로 알려져 있다 (Bruemmer et al., 1986; Kabata-Pendias and Wiacek, 1985; Kabata-Pendias, 2011). 그러나, 용해된 금속-OH 등의 복 합체는 $\mathrm{pH}$ 가 중성 또는 약 알칼리에서 토양에 강하게 흡착 하였다가 강알칼리에서 다시 용해되기도 하며, 반대로 금 속-유기물 복합체는 토양 $\mathrm{pH}$ 가 낮아지면 토양에 강하게 흡 착되는 것으로 보고 되고 있다 (Liebe, 1999; Kabata- Pendias, 2011).

우리나라 광산 인근 농경지에서는 $\mathrm{Cd}, \mathrm{Pb}, \mathrm{Zn}$ 과 같은 중 금속이 복합적으로 오염되어 있어서, 오염 농경지에서 자란 농작물의 중금속 함량이 식품의약품안전처 쌀 안전기준인 $\mathrm{Cd}$ $0.2 \mathrm{mg} \mathrm{kg}^{-1} \mathrm{FW}, \mathrm{Pb} 0.2 \mathrm{mg} \mathrm{kg}^{-1} \mathrm{FW}$ 을 초과하는 경우가 빈번하 였다 (배추/시금치: $\mathrm{Cd} 0.2 \mathrm{mg} \mathrm{kg}^{-1} \mathrm{FW}, \mathrm{Pb} 0.3 \mathrm{mg} \mathrm{kg}^{-1} \mathrm{FW}$; $\mathrm{KFDA}, 2006)$. 이러한 농경지 오염은 농작물뿐만 아니라, 토 양 생물, 지하수, 더 나아가 인간에게까지 악영향을 미칠 수 있어 효과적인 복원 방법의 개발이 시급한 실정이다. 농경 지 오염 토양을 복원하기 위한 방법으로 식물정화법, 동전 기법, 토양 세척법, 객토 등이 있으나, 토양의 생물학적, 물 리학적, 화학적 성질을 최대한 변화시키지 않고, in situ에서 단시간 내에 중금속의 이동성과 생물 유효도를 저감시키는 방법들이 많이 사용되고 있는 추세이다 (ISO 17402, 2008).

본 연구에서는 토양 중금속 안정화제로 환경친화적이고, 비용 경제적인 농수산 부산물인 계란껍질을 사용하였다. 온 실 재배 실험을 통하여 계란껍질이 토양 내 $\mathrm{Cd}, \mathrm{Cu}, \mathrm{Pb}, \mathrm{Zn}$
이동태 함량 변화에 미치는 영향과 상추 뿌리와 잎의 흡수 에 미치는 영향을 조사하여, 계란껍질이 토양 내 중금속의 작물 유효도 변화에 미치는 영향을 평가 하고자 하였다.

\section{Materials and Methods}

토양시료 및 계란껍질 준비 실험에 사용된 오염 토양 은 충청남도 서산에 위치한 폐광산 인근 농경지 (Ap, 0-30 cm) 에서 채취하였다 ( $36^{\circ} 53^{\prime} 05.74^{\prime \prime N} \mathrm{~N}$; $\left.126^{\circ} 24^{\prime} 54.01^{\prime \prime} \mathrm{E}\right)$. 농경지 쌀의 $\mathrm{Cd}$ 와 $\mathrm{Pb}$ 함량이 한국 식품의약품안전처 최대 허용치인 0.2 $\mathrm{mg} \mathrm{kg}^{-1} \mathrm{FW}$ (KFDA, 2006)을 각각 초과하여 토양 복원이 필수 적이었다 (토양 함량 아래 참조). 채취한 토양은 음지에서 풍건하여 말린 후, $2 \mathrm{~mm}$ 체걸음을 하였다. 계란껍질은 세척, 건조 $\left(105^{\circ} \mathrm{C}, 3\right.$ days), 분쇄, $1 \mathrm{~mm}$ 체걸음을 한 후, $900^{\circ} \mathrm{C}$ 에서 6시간 소성하여 조제하였다 (Ok et al., 2010). 계란껍질의 주 성분인 $\mathrm{CaCO}_{3}$ 는 소성과정 동안 대부분 $\mathrm{CaO}$ 로 전환되었으나 $\left(\mathrm{CaCO}_{3} \rightarrow \mathrm{CaO}+\mathrm{CO}_{2(\mathrm{~g})}\right.$; Ahmad et al., 2012), 소량의 $\mathrm{CaCO}_{3}$ 는 불완전 연소로 인하여 소성되지 않고 그대로 남아있었다 (Fig. 1 참조). 입자 사이즈를 균일하고 미세하게 만들어 반응성을 높여주고, 과량의 무기태 탄소를 제거하기 위하여 조제된 소성 계란껍질 (calcined eggshell: CES)은 입경 $710 \mu \mathrm{m}$ 이하, 흰색의 다공성 분말로써, 온실 재배 실험에 사용되었다.

온실 재배 실험 재배 실험을 위해서 풍건한 오염 토양 에 $\mathrm{CES}$ 를 중량 함량이 각각 $0,1,3,5 \%$ 가 되도록 골고루 혼 합한 후, $1 \mathrm{~kg}$ 씩 포트에 담고, 충분히 물을 준 후, 3 일 동안 안정화시킨 후 사용하였다 $\left(25 \pm 2^{\circ} \mathrm{C}\right.$ ). 상추 (Lactuca sativa $\mathrm{L}$. var. longifolia) 는 plug 묘판에서 발아시킨 후, 발아 후 4주째 에 각각의 포트 (CES $0 \%, \mathrm{CES} 1 \%, \mathrm{CES} 3 \%, \mathrm{CES} 5 \%$ )에 이식 하고, 30 일 동안 온실에서 $25 \pm 2^{\circ} \mathrm{C}$ 에서 생육시켰다. 각 포트 의 토양 수분은 WET sensor (Delta-T Devices Ltd., UK)로 매일 모니터링을 했고, 수분 함량이 22 26\%가 유지되도록 증류수 를 공급했다. 이식 후 30 일째에 상추의 잎과 뿌리를 수확하 여, 수돗물과 증류수로 깨끗이 씻은 후, $85^{\circ} \mathrm{C}$ 에서 $72 \mathrm{~h}$ 동안 오븐에서 건조하였다. 건조된 식물은 분석하기 전에 스테인 리스 강철 분쇄기로 곱게 분쇄하였다. 각 포트의 토양도 음 지에서 풍건한 후, $2 \mathrm{~mm}$ 체걸음을 하고, 화학분석에 사용하 였다. 재배 실험은 2 반복으로 진행하였다. 반복 실험의 변동 계수 (coefficient of variation: $\mathrm{CV}$ )는 $<10 \%$ 이였으나, 중금속 식물체 함량이 낮을 경우 $\left(<1 \mathrm{mg} \mathrm{kg}^{-1}\right), \mathrm{CV}$ 가 $>10 \%$ 인 경우 도 있었다.

토양 및 식물체 분석 토양 일반 화학성과 물리성 [유 기탄소 (SOC), 무기탄소 (SIC), 전기전도도 (EC), 양이온교환 용량 (CEC), 토성] 분석은 농촌진흥청 토양 및 식물체 분석 법 (NIAST, 2000)에 준하여 분석하였다. 토양 $\mathrm{pH}$ 는 ISO 10390 
(2005)에 의거하여 $0.01 \mathrm{M} \mathrm{CaCl}_{2}$ 용액을 사용하여 측정하였 다. 토양 $\mathrm{Cd}, \mathrm{Cu}, \mathrm{Pb}, \mathrm{Zn}$ 전함량은 ISO 11466 (1995) 및 농촌진 흥청 토양화학 분석법 (NIAST, 2010)에 준하여 막자 사발로 간 후 $0.15 \mathrm{~mm}$ 체걸음을 한 토양 시료를 왕수 (conc. $\mathrm{HCl}+$ $\mathrm{HNO}_{3}$ )로 $130^{\circ} \mathrm{C}$ 에서 2시간 분해한 후 ICP-OES (GBC Integra XL Dual, Australia)로 정량 하였다. 토양 내 식물 유효태 함량 을 평가하기 위하여 이동태 함량을 조사하였고, ISO 19730 (2008) 과 Zeien and Bruemmer (1989)에 근거하여, 토양을 $1 \mathrm{M} \mathrm{NH}_{4} \mathrm{NO}_{3}$ 로 24 시간 교반한 후, $65 \% \mathrm{HNO}_{3}$ 로 산처리를 한 후, $\mathrm{Cd}, \mathrm{Cu}$, $\mathrm{Pb}, \mathrm{Zn}$ 을 ICP-OES로 정량 하였다. 식물체 $\mathrm{Cd}, \mathrm{Cu}, \mathrm{Pb}, \mathrm{Zn}$ 전함 량은 식물체 $0.5 \mathrm{~g}$ 을 $10 \mathrm{~mL}$ 산 혼합액 (conc. $\mathrm{HNO}_{3}+$ conc. $\mathrm{H}_{2} \mathrm{SO}_{4}+$ conc. $\mathrm{HClO}_{4}=10: 1:$ 4)으로 $200^{\circ} \mathrm{C}$ 에서 분해시킨 후, $\mathrm{ICP}-\mathrm{OES}$ 로 정량 하였다.

\section{Results and Discussion}

토양 일반 화학적 특성 변화 Table 1에서 보는 것처 럼, 온실 재배 실험과 $\mathrm{CES}$ 처리하기 전 토양 $\mathrm{pH}\left(\mathrm{CaCl}_{2}\right)$ 는 5.4 로 중산성 (moderately acidic)이였고, 유기탄소 (SOC) 함량은 $12.6 \mathrm{~g} \mathrm{~kg}^{-1}$ 로 우리나라 농경지 유기물 적정 수준 (논토양. 25 30 $\mathrm{g} \mathrm{kg}^{-1}$; 밭토양: $20-30 \mathrm{~g} \mathrm{~kg}^{-1}$; 유기물 함량 $=$ 유기탄소 *1.724) 과 유사하였다 (NIAST, 2008). 무기탄소 (SIC) 함량도 $1.3 \mathrm{~g} \mathrm{~kg}^{-1}$ 으로 소량 함유되어 있었다. 토성은 식양토 (점토 함량: 29.3\%) 였고, $\mathrm{CEC}$ 는 $10.3 \mathrm{cmol}_{\mathrm{c}} \mathrm{kg}^{-1}$ 으로 우리나라 농경지 토양의 평 균적인 값을 보여 주었다. 전기전도도 $(\mathrm{EC})$ 값은 비교적 높 아 $2.3 \mathrm{dS} \mathrm{m}^{-1}$ 였다. $\mathrm{Cd}, \mathrm{Cu}, \mathrm{Pb}, \mathrm{Zn}$ 의 전함량은 각각 $8.79,65.4$, $1602,692 \mathrm{mg} \mathrm{kg}^{-1}$ 으로, 농경지 토양오염우려기준인 $\mathrm{Cd} 4 \mathrm{mg}$

Table 1. Chemical and physical properties of the investigated soil before greenhouse study.

\begin{tabular}{|c|c|}
\hline Horizon & Ap \\
\hline Depth, cm & $0-30$ \\
\hline $\mathrm{pH}\left(\mathrm{CaCl}_{2}, 1: 5\right)$ & 5.4 \\
\hline $\mathrm{EC}\left(\mathrm{H}_{2} \mathrm{O}, 1: 5\right), \mathrm{dS} \mathrm{m}^{-1}$ & 2.3 \\
\hline Soil total carbon, $\mathrm{g} \mathrm{kg}^{-1}$ & 13.9 \\
\hline Soil organic carbon, $\mathrm{g} \mathrm{kg}^{-1}$ & 12.6 \\
\hline Soil inorganic carbon, $\mathrm{g} \mathrm{kg}^{-1}$ & 1.3 \\
\hline CEC, cmolc $\mathrm{kg}^{-1}$ & 10.3 \\
\hline Total $\mathrm{Cd}, \mathrm{mg} \mathrm{kg}^{-1}$ & 8.79 \\
\hline Total $\mathrm{Cu}, \mathrm{mg} \mathrm{kg}^{-1}$ & 65.4 \\
\hline Total $\mathrm{Pb}, \mathrm{mg} \mathrm{kg}^{-1}$ & 1602 \\
\hline Total $\mathrm{Zn}, \mathrm{mg} \mathrm{kg}^{-1}$ & 692 \\
\hline Texture & Clay loam \\
\hline Clay $(<0.002 \mathrm{~mm}), \mathrm{g} \mathrm{kg}^{-1}$ & 293 \\
\hline Silt $(0.002-0.05 \mathrm{~mm}), \mathrm{g} \mathrm{kg}^{-1}$ & 351 \\
\hline Sand $(0.05-<2 \mathrm{~mm}), \mathrm{g} \mathrm{kg}^{-1}$ & 356 \\
\hline
\end{tabular}

$\mathrm{kg}^{-1}, \mathrm{Cu} 150 \mathrm{mg} \mathrm{kg}^{-1}, \mathrm{~Pb} 200 \mathrm{mg} \mathrm{kg}{ }^{-1}, \mathrm{Zn} 300 \mathrm{mg} \mathrm{kg}^{-1}$ 을 $\mathrm{Cu}$ 를 제외하고 모두 초과하였고, $\mathrm{Pb}$ 는 토양오염대책기준인 600 $\mathrm{mg} \mathrm{kg}^{-1}$ 도 초과하였다 (MOE, 2011).

온실 재배 실험 후 토양 $\mathrm{pH}$ 는 $\mathrm{CES}$ 첨가량이 증가함에 따 라 현저하게 상승하였다 $\left(\mathrm{CES} 0 \%: \mathrm{pH}\left(\mathrm{CaCl}_{2}\right) 5.4 ; \mathrm{CES} 1 \%\right.$ :

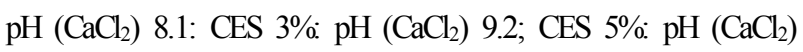
11.1 ; Fig. 1). 이것은 $\mathrm{CES}$ 의 주성분인 $\mathrm{CaO}$ 가 토양 중의 $\mathrm{H}_{2} \mathrm{O}$ 와 반응하여 $\mathrm{OH}$ 를 생성하는 데 기인한다 $\left[\mathrm{CaO}_{(\mathrm{s})}+\mathrm{H}_{2} \mathrm{O}_{(\mathrm{l})} \rightarrow\right.$ $\mathrm{Ca}(\mathrm{OH})_{2(\mathrm{aq})}$. 토양 무기탄소 함량 또한 CES 처리량이 많아짐 에 따라 증가하였으며 (CES 0\%: $1.3 \mathrm{~g} \mathrm{~kg}^{-1}$; CES 1\%: $2.1 \mathrm{~g}$ $\mathrm{kg}^{-1}$ : CES 3\%: $4.8 \mathrm{~g} \mathrm{~kg}^{-1}$; CES 5\%: $7.9 \mathrm{~g} \mathrm{~kg}^{-1}$ ), 이것은 일부 소 성되지 않고 남아있던 $\mathrm{CaCO}_{3}$ 함량에 기인하는 것으로 판단 된다 (Fig. 1). $\mathrm{CES}$ 첨가가 토양 $\mathrm{CEC}$ 와 $\mathrm{Cd}, \mathrm{Cu}, \mathrm{Pb}, \mathrm{Zn}$ 의 전함 량에는 영향을 미치지 않았다.

토양 내 $\mathrm{Cd}, \mathrm{Cu}, \mathrm{Pb}, \mathrm{Zn}$ 이동태 함량 변화 Fig. 2에 서 보는 것처럼, 온실 재배 실험 후 토양 내 $\mathbf{C d}$ 이동태 함량 은 $\mathrm{CES}$ 처리량을 $0 \%$ 에서 $5 \%$ 까지 증가시킴에 따라 3.49에서 $<0.01 \mathrm{mg} \mathrm{kg}^{-1}$ 로 감소하였다 (CES 0\%: $3.49 \mathrm{mg} \mathrm{kg}^{-1}$; CES 1\%: $0.26 \mathrm{mg} \mathrm{kg}^{-1}$ : CES 3\%: $0.08 \mathrm{mg} \mathrm{kg}^{-1}$; CES 5\%: < $0.01 \mathrm{mg} \mathrm{kg}^{-1}$ ). 이것은 $\mathrm{pH}<6.5$ 에서 주로 비특이 흡착, 즉 식물 유효태로 존재하던 $\mathrm{Cd}$ 이 $\mathrm{CES}$ 첨가에 따른 $\mathrm{pH}$ 상승으로 특이 흡착태

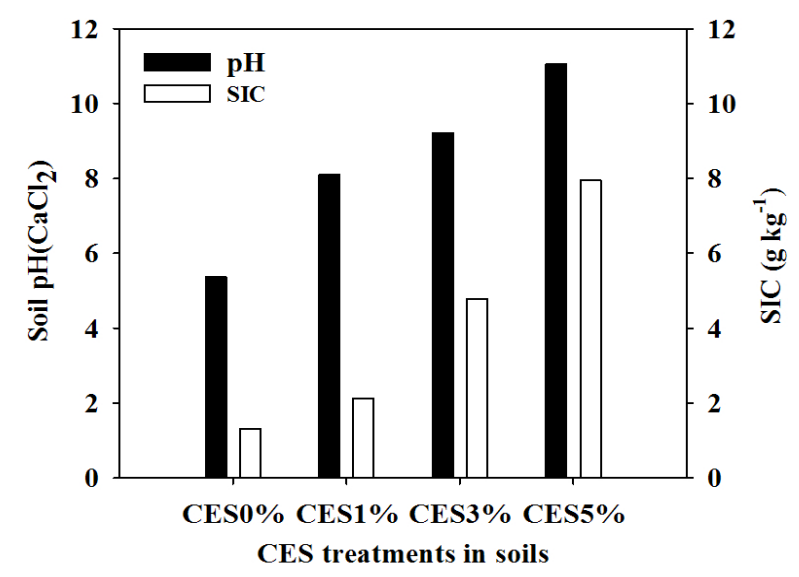

Fig. 1. Soil $\mathrm{pH}\left(\mathrm{CaCl}_{2}\right)$ and soil inorganic carbon (SIC) content after treatment with calcined eggshell.

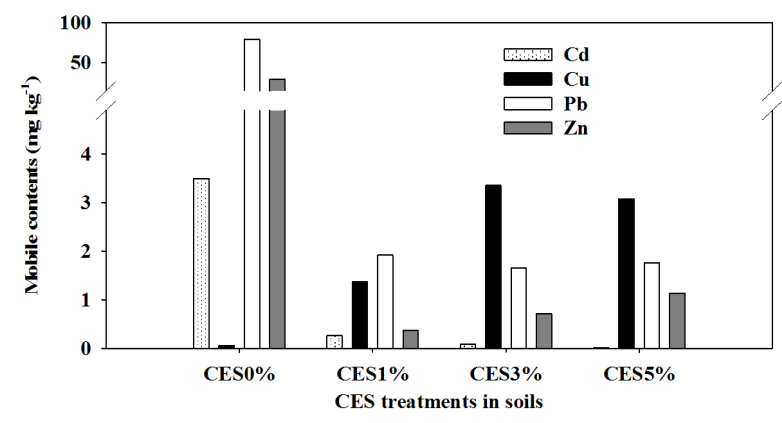

Fig. 2. Mobile contents of $\mathrm{Cd}, \mathrm{Cu}, \mathrm{Pb}$, and $\mathrm{Zn}$ in soils after treatment with calcined eggshell. 
로 바뀌면서, 토양 입자 표면에 강하게 흡착 또는 침전되는 것에 기인하는 것으로 판단된다 (Hornburg and Bruemmer, 1993). $\mathrm{Cd}$ 은 $\mathrm{Zn}$ 와 함께 중금속 중에서 토양 내 이동성이 가장 높은 원소로써, 토양 입자 표면에 흡착력이 낮고, 유기물과 비교적 약한 복합체를 형성하는 것으로 보고되고 있다 (Liebe, 1999). $\mathrm{CES}$ 에 다량으로 함유되어 있던 $\mathrm{Ca}$ 에 의한 $\mathrm{Cd}$ 이동태 함량 증가는 알칼리 조건에서 발견되지 않았다.

$\mathrm{Cu}$ 는 무처리 토양에서 가장 낮은 이동태 함량을 보여 주 었으나 (CES 0\%: $0.05 \mathrm{mg} \mathrm{k}^{-1}$ ), CES 처리량이 증가함에 따라 다른 중금속과 반대로 이동태 함량이 점진적으로 증가하였 다 (CES 1\%: $1.37 \mathrm{mg} \mathrm{kg}^{-1}$; CES 3\%: $3.35 \mathrm{mg} \mathrm{kg}^{-1}$; CES 5\%: 3.08 $\mathrm{mg} \mathrm{kg}{ }^{-1}$; Fig. 2). 이것은 $\mathrm{Cu}$ 가 토양 내에서 주로 $\mathrm{Cu}$-유기복합 체로 존재하며, 이들 복합체는 산성 조건에서는 토양에 강 하게 흡착되지만, 중성 또는 알칼리 조건에서 용해도가 증 가하기 때문인 것으로 판단된다 (Kim et al., 2010). 또한 $\mathrm{Cu}$ 는 $\mathrm{HCO}_{3}^{-}$에 대해 높은 반응성을 가지고 있으며, $\mathrm{CES}$ 첨가로 $\mathrm{CaCO}_{3}$ 함량이 증가됨에 따라 용해성 $\mathrm{CuCO}_{3}^{0}$ 를 형성하여, 알칼리 조 건에서 $\mathrm{Cu}$ 의 이동태 함량을 증가시킨 것으로 판단된다 (Blume et al., 2010). 일반적으로 $\mathrm{Cu}$ 는 토양 $\mathrm{pH}<4.5$ 에서 용해도가 증가하는 것으로 알려져 있지만, $\mathrm{pH}>6$ 에서도 유기물과 유 기 복합체를 형성하여 그 용해도가 증가될 수 있는 것으로 보고 되고 있다 (Kim et al., 2010; Liebe, 1999). 독일에서 제시 하고 있는 농경지 작물독성을 고려한 토양오염 조사기준 1 $\mathrm{mg} \mathrm{kg}^{-1}$ (BBodSchV, 1999)은 모든 처리구에서 초과하였으나, 처리구 상추 잎의 $\mathrm{Cu}$ 함량은 일반적인 성숙한 잎 조직의 $\mathrm{Cu}$ 함량 (5 25 mg kg 범위 내에 있었다 (아래 참고).

$\mathrm{Pb}$ 는 무처리 토양에서 가장 높은 이동태 함량을 보여 주 었으며 (CES $0 \%: 79.4 \mathrm{mg} \mathrm{kg}^{-1}$ ), 이것은 극도로 높은 $\mathrm{Pb}$ 전함 량 (1,602 mg kg$\left.{ }^{-1}\right)$ 에 기인하는 것으로 판단된다 (Fig. 2; Table 1). 그러나 $\mathrm{CES}$ 처리량이 증가함에 따라, $\mathrm{Pb}$ 이동태 함량은 현 저하게 감소하였다 (CES 1\%: $1.92 \mathrm{mg} \mathrm{kg}^{-1}$; CES 3\%: $1.66 \mathrm{mg}$ $\mathrm{kg}^{-1}$; $\mathrm{CES} 5 \%: 1.75 \mathrm{mg} \mathrm{kg}^{-1}$; Fig. 2). 이것은 $\mathrm{pH}$ 상승에 따른 $\mathrm{Pb}$ 의 특이 흡착태 증가에 기인하는 것으로 유추된다. $\mathrm{Pb}$ 는 대 부분 특이 흡착을 하여 토양 입자 표면에 강하게 흡착되는 성질이 있으며, 산성 조건에서는 주로 유기물 결합태로, 중 성 또는 알칼리 토양에서는 $\mathrm{Fe}, \mathrm{Al}, \mathrm{Mn}$ oxides 결합태로 존재 한다 (Blume et al., 2010). 알칼리 토양에서 검출된 $\mathrm{Pb}$ 이동태 함량은 $\mathrm{Pb}$-유기 복합체, $\mathrm{PbCO}_{3}{ }^{0}$ 로 유추되며, $\mathrm{Cu}$ 다음으로 이 동태 함량이 높았다.

$\mathrm{Zn}$ 은 무처리 토양에서 $\mathrm{Pb}$ 다음으로 높은 이동태 함량을 보여 주었으나 (CES 0\%: $29.6 \mathrm{mg} \mathrm{kg}^{-1}$ ), $\mathrm{CES}$ 첨가로 인한 $\mathrm{pH}$ 상승은 $\mathrm{Zn}$ 이동태 함량을 현저히 감소시켰고, 강알칼리 토 양에서 미량 증가하는 경향을 보였다 (CES $1 \%: 0.37 \mathrm{mg} \mathrm{kg}^{-1}$; CES 3\%: $0.71 \mathrm{mg} \mathrm{kg}^{-1}$; CES 5\%: $1.13 \mathrm{mg} \mathrm{kg}^{-1}$; Fig. 2). 알칼리 토양에서 검출된 이동태 함량은 주로 $\mathrm{ZnCO}_{3}^{0}$ 일 것으로 유
추된다 (Zeien, 1995). Cd과 유사하게 유기물과는 비교적 약한 금속-유기 복합체를 형성하기 때문에 $\mathrm{Zn}$ 의 토양 흡착력은 주로 $\mathrm{pH}$ 에 의해 강하게 영향을 받는다.

CES 처리 토양 (CES $3 \%, 5 \%$ )에서 이동태 함량은 $\mathrm{Cu}>\mathrm{Pb}$ $>\mathrm{Zn}>\mathrm{Cd}$ 순서였고, 이것은 이들 원소들의 전함량 순서 $(\mathrm{Pb}$ $>\mathrm{Zn}>\mathrm{Cu}>\mathrm{Cd}$ )와 상이했다 (Fig. 2). 이것은 이동태 함량이 전함량 보다는 $\mathrm{pH}$ 와 원소 특유의 $\mathrm{HCO}_{3}^{-}$와 유기 복합체에 대 한 반응성에 더 영향을 받는다는 것을 보여주는 결과였다.

작물체 내 $\mathbf{C d}, \mathbf{C u}, \mathbf{P b}, \mathbf{Z n}$ 함량 변화 Fig. 3에서 보 는 것처럼, 상추 잎의 $\mathrm{Cd}$ 함량은 $\mathrm{CES}$ 처리에 따른 $\mathrm{pH}$ 증가 와 이동태 함량의 감소로 알칼리 토양에서 현저히 감소하였 다 (CES 0\%: $4.19 \mathrm{mg} \mathrm{kg}^{-1}$; CES 1\%: $1.86 \mathrm{mg} \mathrm{kg}^{-1}$; CES 3\%: 0.03 $\mathrm{mg} \mathrm{kg}^{-1}$; CES 5\%: $<0.001 \mathrm{mg} \mathrm{kg}^{-1}$ ). 상추 뿌리의 $\mathrm{Cd}$ 함량 역시 $\mathrm{pH}$ 증가에 따라 감소하였고, 상추 잎 $\mathrm{Cd}$ 함량의 약 0.5 배 였 다 (CES 0\%: $2.08 \mathrm{mg} \mathrm{kg}^{-1}$; CES 1\%: $0.88 \mathrm{mg} \mathrm{kg}^{-1}$; CES 3\%: 0.04

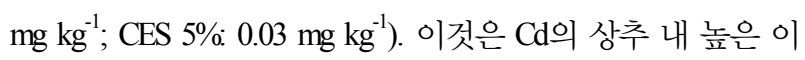
동성을 보여 준다. 상추 잎 건물중이 생체중의 약 $10 \%$ 인 것 을 고려할 때, CES $1 \%$ 처리시 상추 잎 $\mathrm{Cd}$ 함량이 $0.186 \mathrm{mg}$ $\mathrm{kg}^{-1} \mathrm{FW}, \mathrm{CES} 3 \%$ 처리시 $0.003 \mathrm{mg} \mathrm{kg}^{-1} \mathrm{FW}, \mathrm{CES} 5 \%$ 처리시 < $0.001 \mathrm{mg} \mathrm{kg}^{-1} \mathrm{FW}$ 로, 식품의약안전처 배추/시금치 $\mathrm{Cd}$ 안전기 준 $0.20 \mathrm{mg} \mathrm{kg}^{-1} \mathrm{FW}$ 를 모두 만족하였다 (KFDA, 2006).

$\mathrm{Cu}$ 의 상추 내 함량은 다른 원소와 다르게 $\mathrm{pH}$ 증가와 함께 잎과 뿌리 모두에서 증가하였고, 이것은 $\mathrm{CES}$ 처리에 따라 이동태 함량이 증가하였기 때문이다 (잎: CES 0\%: $3.79 \mathrm{mg}$ $\mathrm{kg}^{-1}$; CES 5\%: $6.51 \mathrm{mg} \mathrm{kg}^{-1}$; 뿌리: CES 0\%: $6.12 \mathrm{mg} \mathrm{kg}^{-1}$; CES $5 \%: 10.4 \mathrm{mg} \mathrm{kg}^{-1}$; Fig. 3). 식물 생육에 필수적인 미량영양원 소인 $\mathrm{Cu}$ 는 과량으로 존재할 경우 독성을 나타낼 수 있지만 (Maksymiec et al., 2007), 모든 처리구의 $\mathrm{Cu}$ 함량이 정상의 범 위에 있었고, 독성 증후도 발견되지 않았다. $\mathrm{Cu}$ 는 상추 내에 서 비교적 낮은 이동성을 보여 주었으며, 상추 뿌리의 $\mathrm{Cu}$ 함 량이 잎 함량의 약 1.6 배였다.

$\mathrm{Pb}$ 의 상추 내 함량은 $\mathrm{CES}$ 처리후 $\mathrm{pH}$ 증가와 이동태 함량 의 감소로 잎과 뿌리 모두에서 현저하게 감소하였다 (잎: CES 0\%: $0.78 \mathrm{mg} \mathrm{kg}^{-1}$; CES 5\%: $<0.001 \mathrm{mg} \mathrm{kg}^{-1}$; 뿌리: CES 0\%: $12.9 \mathrm{mg} \mathrm{kg}^{-1}$; CES 5\%: $0.08 \mathrm{mg} \mathrm{kg}^{-1}$; Fig. 3). $\mathrm{Pb}$ 는 $\mathrm{Cu}$ 와 유 사하게 상추 내에서 아주 낮은 이동성을 보여 주었고, 뿌리 함량이 잎의 약 17 배였다. 상추 잎의 $\mathrm{Pb}$ 함량은 식품의약안 전처 배추/시금치 안전기준인 $0.30 \mathrm{mg} \mathrm{kg}^{-1} \mathrm{FW}$ 을 모든 처리 구에서 만족시켰다 (KFDA, 2006).

$\mathrm{Zn}$ 은 식물 미량영양원소로서, 상추 내 함량이 다른 중금 속에 비하여 현저히 높았다 (Fig. 3). 일반적으로 성숙한 잎 의 정상적인 $\mathrm{Zn}$ 함량은 $25-150 \mathrm{mg} \mathrm{kg}^{-1}$ 으로 알려져 있고, 과 량으로 존재할 경우 독성을 유발할 수 있다 (Benton et al., 1991; Kabata-Pendias, 2011). 무처리 토양의 상추 잎 Zn 함량 은 $133 \mathrm{mg} \mathrm{kg}^{-1}$ 으로 독성 범위 100 (150) $400 \mathrm{mg} \mathrm{kg}^{-1}$ 에 인접 
해 있었다 (Kabata-Pendias, 2011). CES 첨가로 인한 $\mathrm{pH}$ 증가 와 이동태 함량의 감소는 잎과 뿌리의 $\mathrm{Zn}$ 흡수를 감소시켰 다 (잎: $\mathrm{CES} \mathrm{0 \% :133} \mathrm{mg} \mathrm{kg}{ }^{-1}$; CES 5\%: $50.0 \mathrm{mg} \mathrm{kg}^{-1}$; 뿌리: CES 0\%: $180 \mathrm{mg} \mathrm{kg}^{-1}$; CES 5\%: $82.4 \mathrm{mg} \mathrm{kg}^{-1}$; Fig. 3). Zn은 상추 내 에서 비교적 골고루 분포하였고, 뿌리의 $\mathrm{Zn}$ 함량은 잎의 약 1.4 배였다.
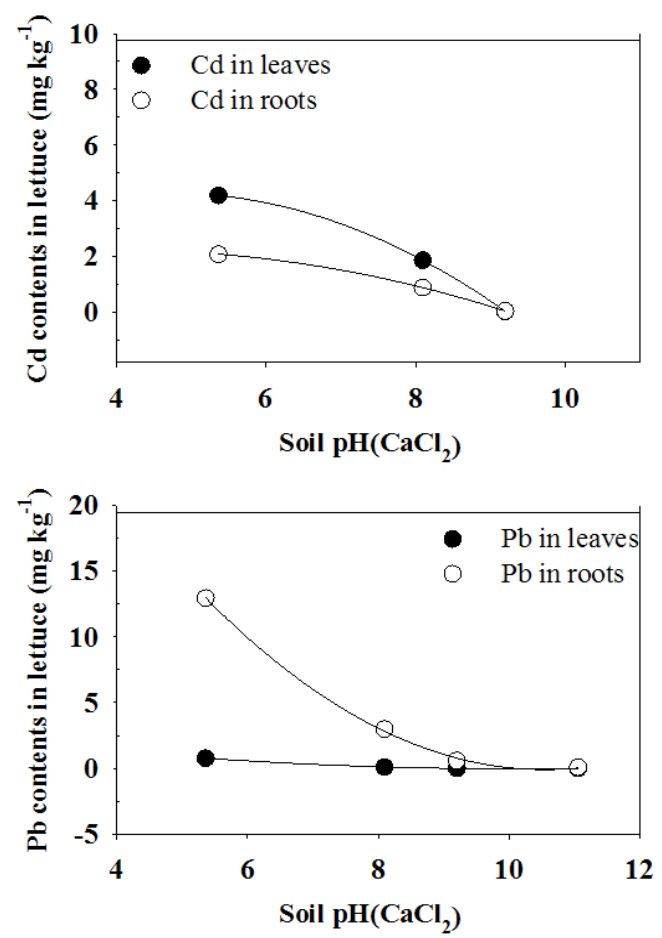

토양 내 이동태 함량과 식물 유효도와의 관계 Fig. 4에서 보는 것처럼, 상추의 $\mathrm{Cu}$ 함량은 토양 내 이동태 함량 이 증가함에 따라 높아지는 정의 상관관계를 보여 주었다. 상추의 $\mathrm{Cd}, \mathrm{Pb}, \mathrm{Zn}$ 함량은 $\mathrm{Cu}$ 처럼 명확하지는 않으나, $\mathrm{CES}$ 처리후, 토양 내 이동태 함량이 감소함에 따라 상추의 $\mathrm{Cd}$, $\mathrm{Pb}, \mathrm{Zn}$ 흡수도 감소하는 것으로 나타났다. 일반적으로 식물


Fig. 3. $\mathrm{Cd}, \mathrm{Cu}, \mathrm{Pb}$, and $\mathrm{Zn}$ contents in lettuce roots and leaves depending on soil $\mathrm{pH}\left(\mathrm{CaCl}_{2}\right)$ after treatment with calcined eggshell.
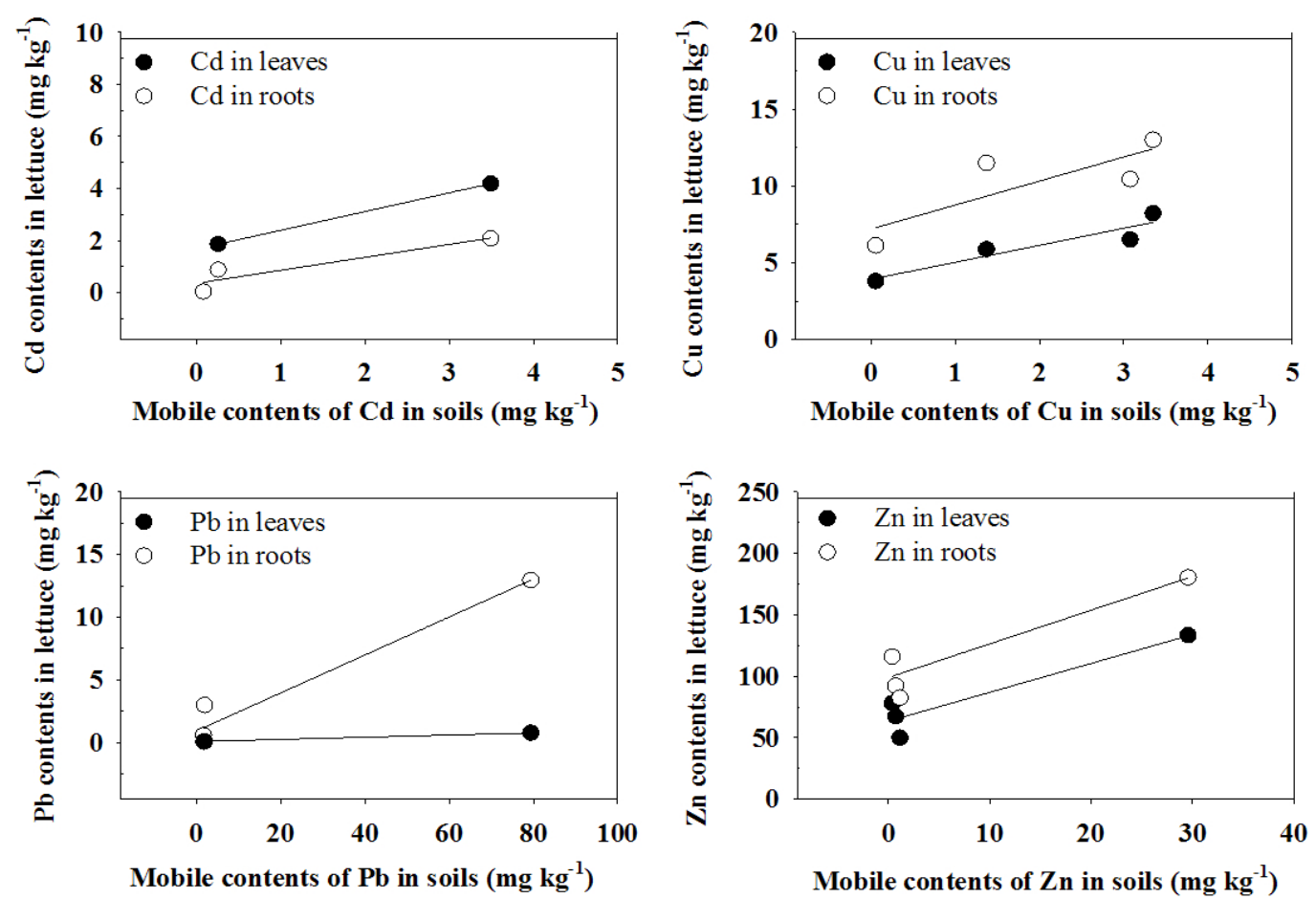

Fig. 4. Relationship between mobile contents of $\mathrm{Cd}, \mathrm{Cu}, \mathrm{Pb}$, and $\mathrm{Zn}$ in soils and their contents in lettuce roots and leaves. 
뿌리는 토양 용액 중에 존재하는 원소만 흡수할 수 있으며, 미량 영양원소인 $\mathrm{Cu}$ 와 $\mathrm{Zn}$ 는 대사 에너지를 사용하는 능동적 흡수를, $\mathrm{Pb}$ 와 $\mathrm{Cd}$ 은 확산, 대류작용에 의한 수동적 흡수를 하 는 것으로 알려져 있다 (ISO 17402, 2008; Kabata-Pendias, 2011). 그러나 토양 용액 중 농도가 높을 경우 $(>0.1 \mathrm{mM})$, 주로 수 동적 흡수를 하는 것으로 보고 되고 있으며, 토양 중에 존재 하는 무기, 유기 복합체는 자유이온인 $\mathrm{Me}^{2+}$ 보다 일반적으로 식물 유효도가 낮은 것으로 보고 되고 있다.

\section{Conclusions}

본 연구에서는 음식 폐기물인 계란 껍질을 활용하여 오 염된 농경지에 존재하는 중금속의 식물 유효도 변화를 조사 하였다. 계란껍질의 첨가 $(1,3,5 \% \mathrm{~W} / \mathrm{W})$ 는 토양 $\mathrm{pH}$ 와 $\mathrm{CaCO}_{3}$ 함량을 증가시켜 $\mathrm{Cd}, \mathrm{Pb}, \mathrm{Zn}$ 의 이동태 함량을 감소시켰으며, 이로 인한 상추 뿌리의 이들 중금속의 흡수를 감소시켰다. 반대로 미량영양원소인 $\mathrm{Cu}$ 는 토양 내 이동태 함량이 증가하 여, 상추 뿌리의 $\mathrm{Cu}$ 흡수가 상승했으며, 상추 잎의 $\mathrm{Cu}$ 함량 도 증가했다. 독성 기준을 초과했던 상추 잎의 $\mathrm{Cd}$ 과 $\mathrm{Zn}$ 함량 은 계란껍질 $1 \%$ 처리로 독성 기준 이하로 감소될 수 있었다. 토양 내 이동태 함량은 이들 중금속의 식물 유효도를 비교 적 잘 반영해 주었다.

\section{References}

Ahmad, M., Y. Hashimoto, D.H. Moon, S.S. Lee, and Y.S. Ok. 2012. Immobilization of lead in a Korean military shooting range soil using eggshell waste: An integrated mechanistic approach. Journal of Hazardous Materials. 209-210:392-401.

BBodSchV (German Federal Soil Protection and Contaminated Sites Ordinance). 1999. BBodSchV vom 12. Juli 1999 (BGB1. I S. 1554), geaendert durch Artikel 2 der Verordnung vom 23. Dezember 2004 (BGBl. I S. 3758). Bundesministerium fuer Umwelt, Naturschutz und Reaktorsicherheit (BMU), Berlin.

Benton, J. Jr., B. Wolf, and H. Mills. 1991. Plant analysis handbook. A practical sampling, preparation, analysis, and interpretation guide. 1. Methods of plant analysis and interpretation. $\mathrm{p}$. 182-183. Micro-Macro Publishing, Inc., GA, USA.

Blume, H.P., G.W. Bruemmer, R. Horn, E. Kandeler, I.KoegelKnabner, R. Kretzschmar, K. Stahr, and B.M. Wilke. 2010. Scheffer/Schachtschabel - Lehrbuch der Bodenkunde. 16th ed. p.435-437. Spektrum Akademischer Verlag, Heidelberg, Berlin, Germany.

Bruemmer, G.W., J. Gerth, and U. Herms. 1986. Heavy metal species, mobility and availability in soils. J. Plant Nutr. Soil Sci. 149:382-398.

Derz, K., C. Bernhardt, D. Hennecke, and W. Kördel. 2012. Ansätze zur Bewertung der Verfügbarkeit von Schadstoffen im nachsorgenden Bodenschutz - Teil II: Verfügbarkeit für
Stofftransport und Abbauprozesse in Böden. Bodenchutz 4:108-112.

Gupta, S.K., M.K. Vollmer, and R. Krebs. 1996. The importance of mobile, mobilisable and pseudo total heavy metal fractions in soil for three-level risk assessment and risk management. The Science of the Total Environment. 178:11-20.

Hornburg, V. and G.W. Bruemmer. 1993. Verhalten von Schwermetallen in Boeden. I. Untersuchungen zur schwermetallmobilitaet. Z. Planzenernaehr. Bodenk. 156:467-477.

Hund-Rinke K. and W. Koerdel. 2003. Underlying issues in bioaccessibility and bioavailability: experimental methods. Ecotoxicology and Environmental Safety. 56:52-62.

ISO 10390. 2005. Soil quality - Determination of $\mathrm{pH}$. International organization for standardization. Switzerland.

ISO 11466. 1995. Soil quality - Extraction of trace elements soluble in aqua regia. International organization for standardization. Switzerland.

ISO 17402. 2008. Soil quality - Requirements and guidance for the selection and application of methods for the assessment of bioavailability of contaminants in soil and soil materials. Switzerland.

ISO 19730. 2008. Soil quality - Extraction of trace elements from soil using ammonium nitrate solution. International organization for standardization. Switzerland.

Kabata-Pendias, A. and K. Wiacek. 1985. Excessive uptake of heavy metals by plants from contaminated. Soil Sci. Soc. Am. J. 36:4-33.

Kabata-Pendias, A. 2011. Trace elements in soils and plants. 4th ed. p.253-268, 275-287. CRC Press, WA, USA.

KFDA (Korean food and drug administration). 2006. Food Safety standards.

Kim, K.-R., Gary Owens, Ravi Naidu, and Kye-Hoon Kim. 2007. Assessment techniques of heavy metal bioavailability in soil - A critical Review. Korean J. Soil Sci. Fert. 40:311-325.

Kim, R.Y., J.K. Sung, J.Y. Lee, Y.J. Lee, S.J. Jung, J.S. Lee, and B.C. Jang. 2010. Accumulation, Mobility, and Availability of Copper and Zinc in Plastic Film House Soils Using Speciation Analysis. Korean J. Soil Sci. Fert. 43:937-944.

Lanno, R., J. Wells, J. Conder, K. Bradham, and N. Basta. 2004. The bioavailability of chemicals in soil for earthworms. Ecotox. Env. Safety. 57:39-47.

Liebe, F. 1999. Spurenelemente in Boeden und Pflanzen Nordrhein-Westfalens - Gehalte verschiedener chemischer Fraktionen in Boeden und deren Beziehung zur Bodenreaktion und den Gehalten in Pflanzen. Ph.D. Thesis, p. 375, University of Bonn, Bonn.

Maksymiec, W. and Z. Krupa. 2007. Effects of methyl jasmonate and excess copper on root and leaf growth. Biologia lantarum. 51:322-326.

Meers, E., R. Samson, F.M.G. Tack, A. Ruttens, M. Vandegehuchte, J. Vangronsveld, and M.G. Verloo. 2007. Phytoavailability assessment of heavy metals in soils by single extractions and 
accumulation by Phaseolus vulgaris. Environ. Experim. Botany, 60:385-396.

MOE, 2011. Enforcement Decree of the Soil Environment Conservation Act. 12th. amended. No. 333. 2009.6.25. Ministry of Environment, Gwacheon, Korea (In Korean).

NIAST. 2000. Methods of soil and plant analysis. National Institute of Agricultural Science and Technology. RDA. Suwon, Korea.

NIAST. 2008. Monitoring project on Agri-Environment quality in Korea. National Academy of Agricultural Science. RDA. Suwon, Korea.

NIAST, 2010. Methods of chemical analysis for soil. National Academy of Agricultural Science. RDA, Suwon, Korea.

Ok, Y.S., S.S. Lee, W.T. Jeon, S.E. Oh, A.R.A. Usman, and D.H.
Moon. 2010. Application of eggshell waste for the immobilization of cadmium and lead in a contaminated soil. Environ. Geochem. Health. 33:31-39.

Semple, K.T., K.J. Doick, K.C. Jones, P. Burauel, A. Craven, and H. Harms. 2004. Defining bioavailability and Bioaccessibility of Contaminated Soil and Sediment is Complicated. Environ. Sc.Technol. 38:228A-231A.

Zeien, H. and G.W. Bruemmer. 1989. Chemical extractions to identify heavy metal binding forms in soils. Mitt. Dt. Bodenkundl. Ges. 59:505-510.

Zeien, H. 1995. Chemical extractions to identify heavy metal biding forms in soils. Ph.D. Thesis, p. 284, University of Bonn, Bonn. 